\title{
Masquander of Peripheral Manifestation of Infective Endocarditis: Purpura Fulminanas
}

\section{Neeraj Awasthy*, Chaya Kumari and Radhakrishnan S}

Department of Pediatric Cardiology and Congenital Heart Diseases, Fortis Escorts Heart Institute, Okhla Road, New Delhi, 110025, India

Keywords: Purpura fulminance; Cyanotic heart disease; Ventricular septal defect

\section{Introduction}

Purpura fulminance is an infrequent acute cutaneous manifestation resulting from infective and non-infective conditions [1,2]. When a patient of known congenital cyanotic heart disease presents with peripheral skin rashes the initial cause that usually comes to mind is infective endocarditis. We present a similar case of a post-operative TGA. This case is presented to emphasizes that all rashes in congenital heart disease is not due to infective endocarditis and one think of other rare possibilities.

\section{Case Report}

6 months old male child was admitted with history of fever for 6 days and blackening of toes for 4 days. It started from bilateral toes and spread upwards towards knees. Later involved left upper limb upto elbows. He was a diagnosed case of transposition of great arteries with ventricular septal defect and underwent arterial switch operation and ventricular septal defect closure at 2 months of age with uneventful postoperative course and was under regular periodic follow up.

At presentation he had stable vitals. Dry gangrene of finger and toes was present. There was no cyanosis, clubbing, jaundice or edema. Lungs were clear. Precordial examination revealed apex in $5^{\text {th }}$ ICS at mid clavicular line. S1 normal, S2 single. Ejection systolic murmur present at left upper sternal border (no change from the findings at discharge after surgery). Per-abdomen liver and spleen not palpable. Rest of the systemic examination was unremarkable. His investigations showed $\mathrm{Hb}=9.5 \mathrm{~g} / \mathrm{dl}, \mathrm{TLC}=20,700 / \mathrm{cmm}(\mathrm{N} 62 \%)$, platelet $=559000 /$ mcl, high sensitive CRP was raised $(\mathrm{CRP}=13.57 \mathrm{mg} / \mathrm{L}), \mathrm{ESR}=41 \mathrm{~mm}$ at 1 hour, $\mathrm{PT}=19.5$ seconds, aPTT $=26.5$ seconds, $\mathrm{INR}=1.51$. Levels of protein $\mathrm{c}$ and protein $\mathrm{s}$ were within normal limits. Repeated echocardiographic examinations showed laminar flow in left and right ventricular outflow tract with no regurgitation, VSD patch in situ with no residual shunt, normal ventricular function, no evidence of infective endocarditis. Blood culture showed the growth of Streptococcus pneumoniae, sensitive to Inj. Amikacin and Cefotaxime. IV antibiotics a

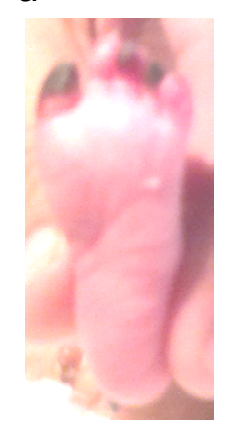

b

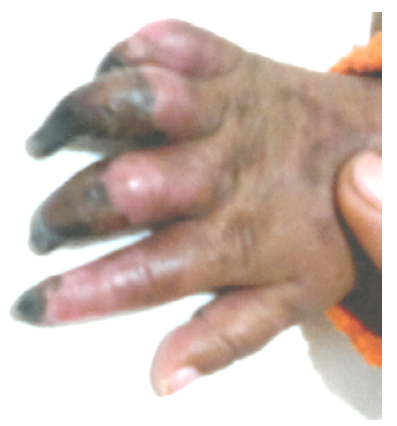

Figure 1a and 1b: Figure shows the gradual progression of the lesions of purpurafulminans over a period of 6 months with conservative management, resulting in sloughing of the distal digits of the upper limbs. were given for 21 days and heparin infusion was given for 7 days. Child responded to treatment, the peripheral rashes started to decrease. Child was discharged on oral Ecosprin. He was regularly followed on OPD basis and during the course of follow up it was observed that the skin lesions markedly decreased with sloughing of the distal digits of the left feet (Figure 1a and 1b) and hand (Figure 2a-2c) in follow up over a period of 6 months. Child is under regular follow up and is doing well.

\section{Discussion}

$\mathrm{PF}$ is a acute onset disorder characterized by cutaneous hemorrhage and necrosis caused by dermal vascular thrombosis. Common antecedent infections are group A Streptococcus, Staphylococcus, Vibrio, Meningococcus and Varicella. Neonates with protein C and Protein S deficiencies are at higher risk for purpura fulminance. Sometime disease may occur without preceding illness [1].Lesion of PF has a characteristic appearance with erythema rapidly followed by irregular central areas of blue-black hemorrhagic necrosis with a surrounding erythematous border. Secondary infection may occur, contributing to late morbidity and mortality. Healing may lead to scarring and auto amputation of digits and extremities, as was observed in our case. Infectious necrosis often begins distally with proximal progression or diffusely over the body, a feature which was characteristically present in our case. Patient who survive are often left with difficult wounds involving underlying a

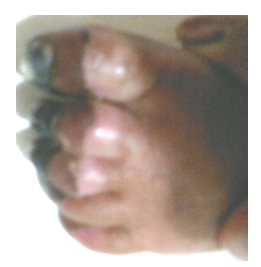

C

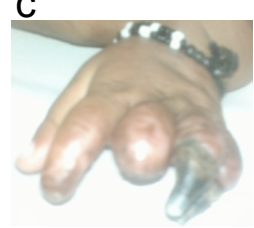

b

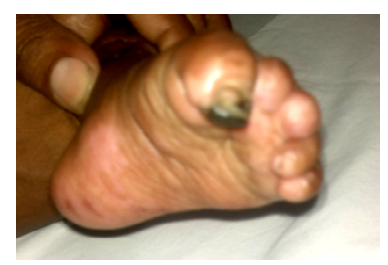

Figure 2a-2c: Figure showing the gradual progression of the lesions of the purpurafulminans over a period of 6 months with gradual sloughing off of distal digits of lower limbs.

*Corresponding author: Neeraj Awasthy, Department of Pediatric Cardiology, $5^{\text {th }}$ Floor, Fortis Escorts Heart Institute, Okhla Road, New Delhi, India, Tel: 09811962775; E-mail: n_awasthy@yahoo.com

Received May 11, 2014; Accepted June 16, 2014; Published June 20, 2014

Citation: Awasthy N, Kumari C, Radhakrishnan S (2014) Masquander of Peripheral Manifestation of Infective Endocarditis: Purpura Fulminanas. J Clin Case Rep 4: 375. doi:10.4172/2165-7920.1000375

Copyright: (c) 2014 Awasthy N, et al. This is an open-access article distributed under the terms of the Creative Commons Attribution License, which permits unrestricted use, distribution, and reproduction in any medium, provided the original author and source are credited. 
Citation: Awasthy N, Kumari C, Radhakrishnan S (2014) Masquander of Peripheral Manifestation of Infective Endocarditis: Purpura Fulminanas. J Clin Case Rep 4: 375. doi:10.4172/2165-7920.1000375

muscles and bone. In our case child was initially diagnosed as a case of infective endocarditis in view of known case of cyanotic heart disease and work-up revealed the growth of Streptococcus pneumoniae. In view of acute manifestation and rapid spread of peripheral rashes with blood culture suggestive of Streptococcus pneumoniae possibility of purpura fulminance became strong. Although it is not justified to exclude the possibility of infective endocarditis, as the etiological organism found in our case is also a common etiological organism for infective endocarditis. What the present case elucidates is, the peripheral manifestation of the infective endocarditis can be resembled by this rare diagnosis of purpura fulminans. Having arrived at the diagnosis still in our opinion the patient needs to be managed on lines of infective endocarditis especially in a setting of a postoperative patient presenting with such lesions [2-4].

\section{References}

1. James WD, Berger TG, Elston DM (2006) Cutaneous vascular diseases Andrews diseases of the skin: clinical dermotology. (10thedn) Philadelphia, $\mathrm{Pa}$ Saunders.

2. Adcock DM, Brozna J, Marlar RA (1990) Proposed classification and pathologic mechanisms of purpurafulminans and skin necrosis. Semin Thromb Hemost 16: $333-340$.

3. Darmstadt GL (1998) Acute infectious purpurafulminans: pathogenesis and medical management. Pediatr Dermatol 15: 169-183.

4. Smith OP, White B (1999) Infectious purpurafulminans: diagnosis and treatment. Br J Haematol 104: 202-207. 